\title{
Publisher Correction: Monitoring key epidemiological parameters of SARS-CoV-2 transmission
}

Moritz U. G. Kraemer (D), Oliver G. Pybus (D), Christophe Fraser (D), Simon Cauchemez (D), Andrew Rambaut (D) and Benjamin J. Cowling (D)

Correction to: Nature Medicine https://doi.org/10.1038/s41591-021-01545-w, published online 8 November 2021.

In the version of this article initially published, a composition error affected the connection of lines in Fig. 1. The diagram has been revised to more clearly delineate transmission stages. The original and corrected Fig. 1 are shown below.
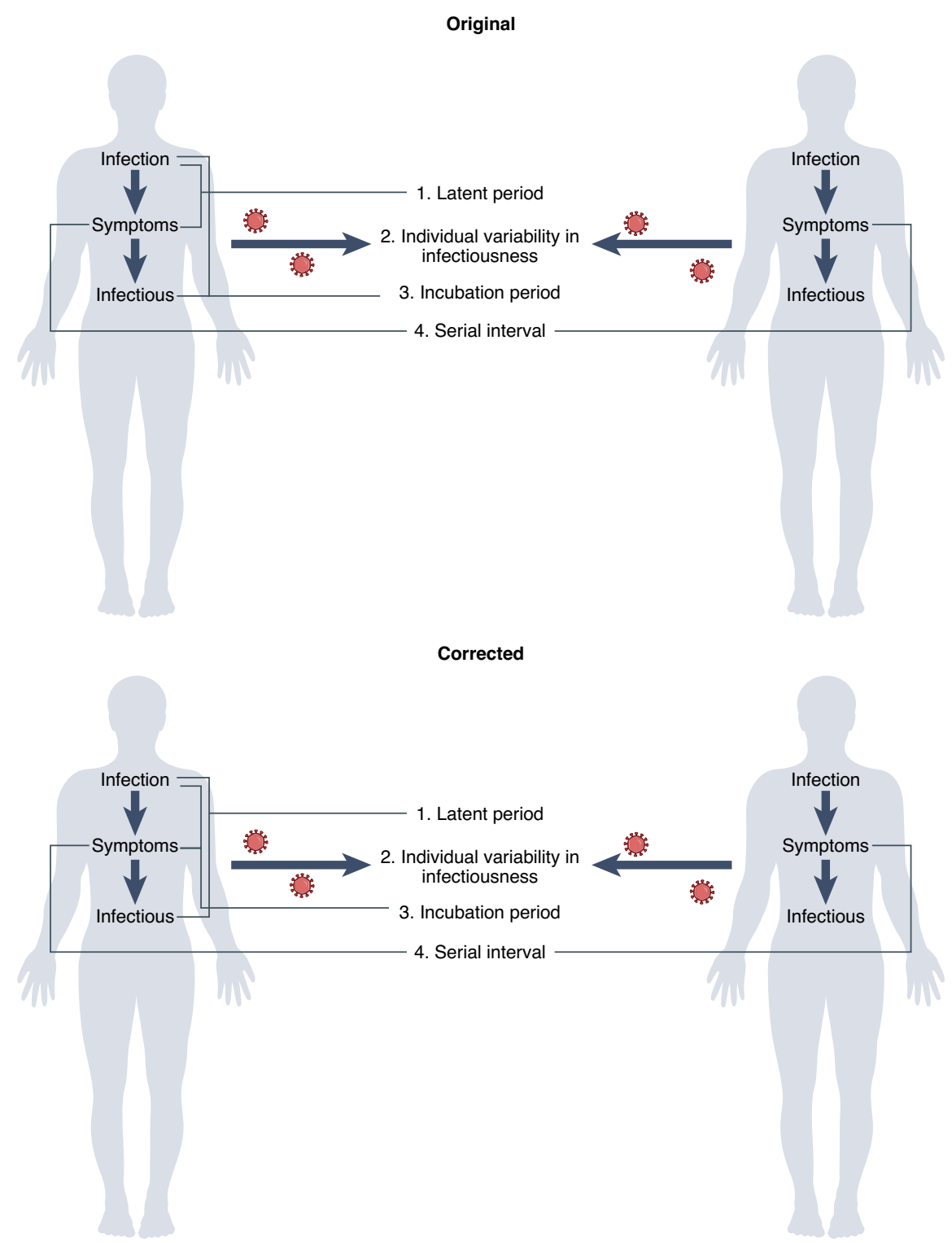

Fig. 1 | Original and Corrected.

Published online: 12 January 2022

https://doi.org/10.1038/s41591-021-01670-6

(c) The Author(s), under exclusive licence to Springer Nature America, Inc. 2021 